\title{
Coming In/Out Together: Queer(ing) schools through stories of difference and vulnerability
}

\author{
Lindsay Cavanaugh* \\ The University of Victoria \\ 1.cavanaugh@rogers.com
}

\begin{abstract}
Over the past few decades, Canada has implemented more equitable laws that delineate movement towards greater acceptance of gender and sexual minorities (e.g. Smith, 2008; Rayside, 2008). Despite these shifts, evidence suggests that public schools remain unsafe and non-affirming spaces for many people who identify as LGBTQ*. While efforts have been made to create safe $(r)$ spaces for students who identify as LGBTQ*, primarily through anti-bullying policies, only a minority of Canadian schools have affirmatively recognized sexual and gender diversity in classroom learning. Some scholars assert that without accompanying curricular reform, anti-bullying work may promote a singular and dichotomized queer narrative: that to be LGBTQ* equates victimhood or resilience. This study - through a qualitative analysis of interviews with two English teachers, surveys from 30 Grade 10 students, and observations from a workshop with a Grade 10 class - explores the role of storytelling as a means for fostering queer-affirming spaces.
\end{abstract}

Keywords: Queer-affirming; curricular reform; inclusion; coming out stories

\section{INTRODUCTION}

We must not see any person as an abstraction. Instead, we must see in every person a universe with its own secrets, with its own treasures, with its own sources of anguish, and with some measure of triumph.

Elie Wiesel, 1992, p. 4

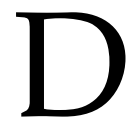

o learners and educators who identify as lesbian, gay, bisexual, transgender, Two-Spirit, queer, intersex, or asexual (LGBTQ*) ${ }^{1}$ feel safe and positively affirmed in Canadian public high schools today? While on my final practicum teaching in a public high school in

*This research was conducted under the supervision of Dr. Kathy Sanford and was supported by the Jamie Cassels Undergraduate Research Award (JCURA). I would like to express my sincerest thanks to Dr. Kathy Sanford for her support in the project, to Ph.D candidate Bruno de Oliveira Jayme for his creative genius, to educator/scholars, Kristin Mimick and David Monk, for their encouragement during the Research Institute for Professional Learning, and to the teachers and students who participated in my study and honoured me with their stories.

${ }^{1}$ LGBTQ* is a shortened acronym for LGBTTQQIAA (lesbian, gay, bisexual, transgender, Two-Spirit, queer, questioning, intersex, asexual, ally). The asterisk $\left(^{*}\right)$ signals that many more identities exist and that these terms are constantly evolving. See Storey \& Fobes (n.d) for more information on terms. 
Victoria, British Columbia, it was difficult to discern how safe and affirmed queer ${ }^{2}$ individuals really felt. I had the belief and hope that schools were becoming more positive for LGBTQ* people. I smiled at the sight of a poster with a quotation stating how same sex marriage was "fabulous". I glowed when I heard the school had a pride club. When I passed out a student survey on my first day asking learners for their preferred names and gender pronouns, most students did not blink an eye. One student said afterward how much she appreciated the option for circling gender pronouns.

Despite this positive reception to talking about gender, studies suggests that if you are a sexual and/or gender minority in a Canadian high school, it is highly likely that you will hear insulting things about your sexual orientation and/or gender identity (Taylor \& Peter, 2011, p. 49). According to Egale's national climate survey (2011), 77\% of female minority students, $76 \%$ sexual minority males, and $82 \%$ of trans* youth hear "that's so gay" every day at school (Taylor \& Peter, 2011, p. 49). Taylor et al.'s Every Teacher Report (2015) echoes this reality, stating that $49 \%$ of educators hear homonegative comments daily or weekly, $41 \%$ hear sexist remarks aimed at girls, and only $30 \%$ of teachers feel that their schools respond effectively to incidents of gender and sexual-based harassment (p.18). While region to region differs greatly in the reported frequencies of students hearing queerphobic language - BC having the lowest $(54 \%)$ and Ontario $(81 \%)$ as well as northern communities having the highest (Taylor et al., 2015, p. 53) - even the lowest frequency is still half of students claiming to hear LGBTQ*-negative talk in schools.

Despite the fact that Canada's extension of legal marriage, workplace advocacy, and overall visibility ranks it as an international leader for LGBTQ* issues (e.g Smith, 2008; Rayside, 2008), gender and sexual minorities not only have to contend with disparaging talk about their identities, but are at a higher risk of hate crimes, bullying, and mental health challenges (e.g. Taylor \& Peter, 2011; Rayside, 2014). Multiple studies also indicate that Canadian students are as likely to be bullied due to real or perceived sexual and gender difference as students from other Western countries, such as the US and UK, who have been less swift in their implementation of equitable laws (e.g. Taylor \& Peter, 2011; Dorais, 2001; McNinch \& Cronin, 2004; Walton, 2004; Saewyc et al., 2006; Saewyc et al., 2007; Chamberland, 2011; Short 2013). So why is it that schools remain unsafe and non-affirming sites for LGBTQ* students when the country appears to be relatively advanced in its legal consideration of LGBTQ* people?

In the sections that follow, I will argue that schools remain unsafe and non-affirming sites for queer individuals because most schools take a more reactive approach towards LGBTQ* people and issues. I name this more cautious approach, marked by anti-bullying rhetoric, a queer safe model. While protection of LGBTQ* people is important, I advocate instead for a more proactive approach: the integration of queer-positive talk in classrooms. I call this alternative a queer-affirming model. Unlike the queer-safe model, I will argue that a queer-affirming approach has the ability to positively visibilize LGBTQ* people, which allows for freer movement in and out of school spaces.

I will also argue that, because educators balance countless tasks such as planning, assessing, communicating and collaborating, they need practical and flexible strategies to transform their classrooms from safe to affirming. I ground this argument for practicality in a qualitative research method that constructs and re-imagines space both through the voices of participants and my own observations as a queer educator who facilitated a workshop with 30 Grade 10 high school students. In the end I will emphasize one strategy for fostering queer-affirming spaces: connective storytelling. The goal of this paper is therefore twofold: to suggest that a queer-affirming model is superior to a purely queer-safe approach; and to offer one strategy — the sharing of personal

\footnotetext{
${ }^{2}$ One use of the term queer is as an umbrella term. In this instance, I am referring to all members of the LGBTTQQIAA community.
} 
stories - as a medium for teachers to realize queer-affirming practice.

\section{A Qualitative Approach: Stories, space, \& Place}

So why stories? When I was a little girl, stories seemed to float around without consequence. I remember the way light would reflect off the pink walls of my small room, the rustle of my dress against my legs as I climbed the backyard elm, the gruff call of my father's voice telling me to come down. As I got older, stories became more pronounced. Expectations settled in. Girls were this; boys were that. There was my mother's voice talking about how disgusting it was that men were meeting other men at the park for you know what. There was that undeniable feeling of indifference as my university roommates ogled some male celebrity while painting fingernails. There was the way my chest began to cave in on itself; how it became difficult to rejoice in the way light would reflect off my now neutral walls. And perhaps mostly palpably there was a resounding silence - an absence. Because to articulate difference - to embody queerness - in a world that propagates sameness can be lonely if realized alone. This became my coming out story. This story is important because I carry it around with me and always have. This story affects how space has shaped me, how it shapes me still, and how I hope to shape it.

As Gildersleeve and Kuntz (2011) explain: "[s]pace, as a dynamic social concept dwells in multiple meanings. There are the material aspects of space - those surroundings we experience through our physiological senses. And, of course, there are the social meanings generated though our interactions with space" (p. 20). In other words, we are constantly creating meaning through what is present and absent - be it other people or inanimate objects. Besides, "these two general ways of experiencing and knowing space, [this] concept has implications for issues of mobility - how socio-cultural and material contexts enable and constrain particular movements through space" (Gildersleeve and Kuntz, 2011, p. 20). When talking about LGBTQ* people, socio-cultural and material contexts certainly figure into their ability to recognize, accept and/or live their queerness openly. Other factors, such as ethnicity, skin colour, able-bodiness, class, and religion influence this ability as well. All those who enter school spaces therefore move and reside within them differently. One question for us as educators, and a central question for this research, is then: How can we foster environments where queer(ed) students can move freely in and out of schools?

One important element stressed in critical geography literature is that spatial analyses should reflect "daily, lived, and embodied elements of social life" (Gildersleeve and Kuntz, 2011, p. 20). Because this research seeks to understand queer people's lived experiences in school, and to improve upon them, it seems crucial to listen to the stories of LGBTQ* and straight/cisgender ${ }^{3}$ folk in navigating school spaces. For this reason, I draw on both my personal experiences as a white, cisgender, able-bodied, queer, female-identified person, and the voices of students and educators from a particular high school to construct how different people experience that space.

Loftus, Higgs, and Trede (2011) note that "[s]ubjectivity is present in all research to some degree and subjective experience is itself a source of valuable insight"(p.3). My research does not attempt to be objective. It is very much embedded with personal narratives and is also concerned with how narratives construct and re-create spaces. I treat these pages as a space that houses and guides us by way of the walls or stairs or hallways it creates. My use and interpretation of stories - both my occasionally narrative tone in this paper, and my qualitative analysis of teacher interviews and survey results from students - strives to accomplish two goals. Firstly, I wish to privilege the lived experiences of learners and educators in the school. This privileging is in alignment with how many qualitative researchers, particularly Wenger (1998), emphasize the importance of practionners sharing their stories so that they could learn from one another (Loftus

\footnotetext{
${ }^{3}$ Cisgender refers to individuals who identify with their biological sex.
} 
et al. 2011, p. 4). Secondly, I hope to embody the strategy that I encourage educators to realize with their students - the sharing of personal stories to foster empathy and connective thinking. As Loftus et al. (2011) writes, "qualitative researchers need to be creative, both in seeing the world differently, and in being able to express this new understanding in ways that help the rest of us understand the world in these new ways" (p. 5). Stories are at the core of this research, and as such, it seems only fair to treat participants as storytellers and to transform my data into a sort of story itself.

\section{Literature ReVieW: From theORY to PRACTICE}

\section{Distinguishing Between Queer-Safe and Queer-Affirming}

Drawing on the idea that space - what is present and absent within it — informs a person's ability to exist authentically, I will now distinguish between the model that the majority of schools maintain regarding LGBTQ* issues, a queer-safe approach, and the model I wish to advocate for, a queer-affirming approach.

A queer-safe approach is reactive, while a queer-affirming model is proactive. A queer-safe space is an environment where, in principle, learners do not fear bullying and/or exclusion because they are or are perceived to be LGBTQ*. In a queer-safe space, educators theoretically intervene if they hear or witness homophobic, biphobic, transphobic and/or sexist remarks and/or behaviour. While intervention is crucial to stop behaviour that harms LGBTQ* people, queer-safe spaces do not necessarily disrupt the thinking that informs discriminatory behaviour. It is a behaviour-curbing approach. A queer-affirming space, on the other hand, is an environment where LGBTQ* individuals and other minorities feel positively acknowledged because individuals learn about each other and about difference in general. In this sort of learning space, people are not picked out as different. All people are understood as different. Teachers are not just responding when they hear queerphobic language; they are utilizing inclusive language themselves and representing diverse identities in the material they teach.

Another way of distinguishing between these two approaches is that anti-bullying efforts represent a queer-safe model while curricular reform signals a queer-affirming model. David Rayside (2014) notes that many provinces have adopted legislation that seeks to protect LGBTQ* people, but that "[n]o education ministry in Canada has taken concerted steps to ensure that there is instructional attention to sexual [and gender] diversity built into the overall curriculum" (p. 203). For example, Ontario was one of first provinces to develop a Violence-Free Schools Policy in 1994 followed by the Safe Schools Act in 2000 (Rayside, 2014, p. 196) but integrating discussion about gender and sexuality into classrooms remains a "political hot button" (Rayside, 2014, p. 191). In principle, Ontario schools are then queer-safe spaces. They have policies that work to combat homophobia; however, just because a school has a policy that prohibits bullying and exclusion based on real or perceived sexual orientation and gender identity does not mean the school is a place where LGBTQ* people feel physically and emotionally safe. This holds true in Ontario where students have the highest recorded rate of hearing queerphobic language in schools (Taylor et al., 2015, p. 53)

Arguably the "pronounced gap between equity policy — and the realities of school classrooms and hallways" (Rayside, 2014, 191) is because these policies are without accompanying curricular reform. Without instruction about gender and sexuality in classrooms, students are only being told what not to do and say towards people they perceive as different; they are not learning about types of difference. Bullying and harassment might be the easier, more palatable policy front (Rayside, 2014, p. 203), but it is not benefiting learners, educators, and community members. A 
shift should be made then from a queer-safe model to a queer-affirming model. British Columbia is the only province which has attempted to create a course, Social Justice 12, that touches on LGBTQ* issues through an activist lens (Rayside. 2014, p. 200). This course, however, is elective and so only reaches students who self-select it. For a school to be queer-affirming, all learners need to be exposed to various forms of being. Queer-safe policies and queer-affirming elective courses are therefore important steps to fostering positive learning spaces, but further curricular reform is needed to support all school stakeholders - learners, educators, and community members.

\section{The (In)visible Queers: The Need to Introduce New Narratives}

One issue with the queer-safe model is that it unintentionally tokenizes LGBTQ* people and their experiences which invisibilizes them. Queer people are already made invisible in schools, because, like our society at large, schools are heteronormative and cisnormative spaces - environments where individuals are assumed to be heterosexual, attracted to the opposite sex, and cisgender, identifying with the sex they were assigned at birth, until proven otherwise (Toomey, McGuire, \& Russell, 2012). Gender separate bathrooms are an example of both hetero and cisnormative thinking; latent in these gendered spaces lurk the binary understanding that people are either male or female, and that "men" are attracted to "women" and vice versa. Within this framework - that goes far beyond bathrooms - there is little room to exist as gay, lesbian, bisexual, transgender etc. Through these assumptions and the behaviour that accompanies them, schools "privileg[e] and sanctio[n] individuals based on presumed binaries of gender and sexuality" (Toomey et al., 2012, p. 188). Moreover, hetero/cisnormativity is so prevalent that, as Mel Freitag (2013) notes, it routinely requires a queer subject entering into hetersexualized and cigendered spaces for non-queer(ed) persons to see that "these streets, malls, motels, and schools have been 'produced as heterosexual"' and cisgender (p. 132). So how can a queer-safe model that seeks to protect LGBTQ* people be heteronormative and cisnormative?

While the queer-safe approach draws attention to LGBTQ* people, it is inherently hetero/cisnormative because it focuses on a small population of queer people - youth - and a single experience that LGBTQ* may or may not experience: bullying. Much of the anti-bullying rhetoric centres around youth (particularly gay and lesbian adolescents) and in doing so forgets to acknowledge the diversity of queer identities — such as people who identify as transgender, Two-Spirit, genderqueer, asexual, and intersex to name a few, and also that many educators and community members are also LGBTQ*. In this way, anti-bullying efforts unintentionally distance queer educators, families, and learners from each other because they shed light on a limited group of LGBTQ* people.

Another issue with the queer-safe approach is that, through its telling of gender and sexualbased harassment, it emphasizes victimhood or resilience. Formby (2015) notes that "[s]chool policy and practice, popular culture, and activism can lead (albeit inadvertently) to an assumption that to be young and LGBT means facing adversity, thus minimising the potential for shared (public) stories of love, friendship and happiness among LGBT young people" (p. 636). She explains that by focusing on dominant bullying and/or suicidal discourses about being LGBTQ*, young people are only exposed to a single queer story (Formby, 2015, p. 636). Learners hear about students being victimized because they are queer, and if queer students overcome this real or imagined victimization, they are resilient. While bullying and harassment can be a very real experience for LGBTQ* youth, it is certainly not an experience that every queer youth will experience. Nor is it reflective of the amazing lives queer people have lived and are living now. It is therefore important to disrupt a singular, dichotomized narrative of the "suffering" or "resilient" queer youth, which "deflect[s] research and pedagogy away from a consideration 
of the operations of hetero[/cis]normativity in schooling towards a focus on individual/group pathology" (Rasmussen \& Crowley, 2004, p. 428-429). Queer visibility should therefore be both positive and encompass all school stakeholders - learners, educators, and community members.

\section{Queer Can Be a Verb Too: Disrupting The Urge to Normalize}

In contrast to using a queer-safe model, fostering queer-affirming spaces - or more succinctly, queering schools - can benefit both LGBTQ* and heterosexual/cisgender school stakeholders. Before explaining the benefits of queer(ed) spaces, it is useful to offer another understanding of the term queer in relation to queer theory and pedagogies.

While queer was once a highly offensive term, and remains contentious both inside and outside the LGBTQ* community, many (primarily gay, lesbian, and bisexual) subjects have used it intentionally to deprive it of the negative connotations it has been assigned. Besides being an umbrella term for the LGBTQ* community, queer has been claimed by theorists to articulate a desire, action, and way of thinking that unsettles binary and normative thinking. Skyes (1998) explains that queer theory developed in the context of sex debates between feminists, critiques of feminism, the rise of postmodern theory, and the right-wing backlash against homosexuality in the AIDS crisis (p. 156). She adds that much queer theory builds from the poststructural/modern work of Foucault and Derrida of the 1970s, and was influenced by French poststructuralism and Lacanian psychoanalysis (p. 156). Drawing on poststructuralism, Rasmussen (2016) explains that queer theorists "argue that the very definition of queer is harmful" and their "object of investigation ... is not the normalcy of queers, but the process of normalization; and the goal of political movement is not assimilation, but deconstruction and disruption" (p. 145). In other words, queer theorists seek to unravel hierarchial relationships such as queer-normal, inside-outside, self-other and other binaries that claim certainty, and privilege one way of being over another.

A queer(ed) space is then an environment that disrupts the privileging of normalcy over difference. A queer(ed) space does not attempt to naturalize differences but instead queers normalcy. In this sort of space, educators, learners, and community members work together to disrupt hetero/cisnormative discourses on an ongoing basis as well as other "normative" ways of thinking. School stakeholders challenge their own belief systems and strive to become more comfortable with difference in all its many forms.

Freitag's (2013) analysis of Unity, an American school pegged as the "gay school", contributes to a greater understanding of a queer(ed) space. In this school where "a student may feel safe to wear a wig or present as a different gender than when they go home for a family barbecue" (p. 146), Freitag defines the school as more of a community space. Jennifer, the restorative justice teacher and facilitator at the school, explains that the main difference between Unity and other schools is that they "listen to the students' stories" (2013, p. 140). This emphasis on student voices paired with the democratic structure of the school creates space for new discourses to emerge. Because the school models to students how to share and be listened to, learners can produce and share stories that expand notions of identity, personhood, and experience. Drawing on Marc Augé's definition of non-places "as places where there [is] ... a discourse of belonging, and places to build community", Freitag (2013) articulates that queer spaces are both non-places and places simultaneously (p. 144). In other words, queer(ed) sites bring people together through a collective sense of difference and uncertainty. Instead of bringing people together through what they have in common, people come together through the ideology that we are all different and unfixed. Difference then becomes the binding force, and an opener for us to examine how our various identities are formed.

This decentering of identity can benefit all school stakeholders. This is because when we 
loosen our grasp on certain identities that we perceive as fixed and we see identity in constant formation, we can make room for new self-stories to emerge; we can allow ourselves and others to navigate spaces more authentically. While this applies directly to LGBTQ* people, others can benefit from having more space to discover how they wish to express and understand themselves. It is important to also understand that "just because an individual identifies as queer, [it] does not mean they automatically queer a space when they enter or reside in it" (Freitag, 2013, p. 130). This is because " $[\mathrm{m}]$ any queer-identified individuals may ... intentionally or unintentionally, want to 'fit in' to the heterosexual matrix" (Freitag, 2013, p. 130). This is not to say that labels are not beneficial or should not be used, but merely that they can be limiting if they are perceived as fixed. Queer(ed) spaces are then not exclusively LGBTQ*; rather they are inclusive to all people. Their deconstruction of fixed identities is beneficial to all because they can undermine the privileging of certain ways of being over others.

\section{The Study: Fear, doubt \& STORYTELling}

\section{Overview}

Through my literature review, I confirmed two suspicions: that while progress has been made in many arenas for LGBTQ* people, schools can and should be more inclusive; and that curricular reform is the key to realizing queer affirming spaces. I also uncovered that sharing and listening to stories - in the spirit of Unity, both the school and connective way of being — can be a strategy for helping school stakeholders become more comfortable decentering identities.

After establishing that I wanted to queer a classroom through stories, I began my study by applying for human ethics approval so I could work directly with educators and learners. At the time, I was on my final practicum at a large local public high school with a predominately white, middle/upper class population. In my human ethics approval application, I requested to interview teachers and facilitate a workshop with one of the Grade 10 English classes that I would be teaching. In the end, I interviewed two English teachers, facilitated a workshop for 30 Grade 10 students, and analyzed their pre and post-workshop surveys. In the sections below, I will discuss my findings.

\section{We Can Say Queer? Teachers Need Knowledge and Confidence}

After receiving consent from educator participants, I interviewed two teachers. The interviews were confidential and the teacher's responses were transcribed with no identifying marks. Even though teachers expressed interest in participating in the study, this precaution was taken to provide participants with a greater sense of safety in discussing their opinions honestly. Both educators identify as cisgender and heterosexual. One participant was female-identified and the other was male-identified. In this paper, I will refer to them as Karen and Stephen; these names are pseudonyms and in no way reflect the participants' true names. Both Karen and Stephen have been teaching for at least ten years and both indicated a strong desire to integrate LGBTQ* content into their classrooms. I asked Karen and Stephen the following questions one-on-one.

\section{Teacher Interview Questions}

1. How do you feel about teaching gender and sexuality in your class?

2. Do you feel comfortable teaching gender and sexuality in your class? 
3. Do you want to integrate more learning about gender and sexuality into your class? Do you feel it has a place in the classroom? Why or why not?

4. You may decline to answer. Have you worked with staff in schools who self-disclosed as queer-identified?

5. Do you feel staff members would feel safe to disclose their gender and/or sexual orientations with other staff members? With their students?

6. You may decline to answer. If you feel comfortable, do you mind disclosing your gender identity or sexual orientation?

7. Do you consider yourself a queer role model or LGBTQ* ally in the school? Why or why not?

8. Do you feel you have enough knowledge and resources to talk about gender and sexuality in your class?

9. What resources would you like to see more of? Why or why not?

Participants were not made aware of what the other had said. I will discuss their responses in two groupings. In response to questions 1, 2, 3, 8, 9 both interviewees stated they felt integrating LGBTQ* content into classrooms was necessary, but they felt they lacked information and resources. Stephen said: "It's a must. [LGBTQ* content] needs to be in my curriculum and all curriculum. It shouldn't be [the] focus, but woven throughout". When I asked him to explain that comment a little more, he articulated that sometimes LGBTQ* content feels tokenized and he believes it shouldn't be a special topic, but an everyday aspect in learning. When asked about her feelings, Karen stated: "I am willing to [integrate LGBTQ* content into my class], and feel it is very important, but I do not feel informed". She also listed efforts she had already tried in her classroom: such as researching texts with queer characters and trying to invite Ivan Coyote, a queer spoken word poet, as a guest speaker. She described both tasks as difficult to realize.

When asked about what resources she would like to see more of, Karen said: "it would be helpful to have a way of teaching kids the basics of the terms, the sameness of the lives of LGBTQ citizens. We need to see more literature." Stephen echoed Karen's feeling of wanting more complex texts that he could introduce in his English classes. He emphasized that he would want texts where LGBTQ* characters are just woven into the storylines, not sticking out for their perceived difference. Overall, both teachers articulated that more information and subject-specific resources would help them feel more comfortable and capable integrating LGBTQ* content into their classrooms. This corresponds with Taylor et al.'s Every Teacher Report (2015) that notes self-efficacy as a significant factor in whether or not teachers will engage with LGBTQ* issues in their classrooms.

When asked about question 5, 6, 7 - questions about queer and non-queer staff members and their roles - Karen and Stephen both indicated they were cisgender and heterosexual. They stated they had worked with LGBTQ*-identified educators in the past. Neither teacher addressed how safe they perceived their work environment for LGBTQ* staff members. This absence could be a result of them not feeling comfortable speculating about an experience they would not have first-hand experience living. When asked about how they consider themselves, Karen considered herself an ally. She stated: "personal experiences with gay acquaintances have helped me better understand their struggles, their sameness, [h]owever, I fear I am more of a silent ally in that I don't protest, or join parades... I try to teach acceptance in my classroom." This statement suggests that Karen perceives being an ally as someone with a more active role than just "teach[ing] 
acceptance". Stephen, on the other hand, gave a different response when asked about how he saw this role. Firstly, he stated that he was an ally, and then he added that he actually did see himself as a queer role model because he felt that someone "doesn't need to be queer to be a role model for queer people". When I asked him to explain this further, he articulated that he felt that "start[ing] with heart" - coming at the topic of gender and sexuality with openness and compassion - might be his best option at being an ally or role model for LGBTQ* students. Ultimately, both teachers saw their roles for LGBTQ* people as important. While neither had a formula for fostering queer-affirming spaces, Stephen's compassion-first approach paralleled the way that I approach talking and teaching people about sexual and gender diversity.

\section{Queer Is What? Initial Student Responses}

After speaking with teachers, I turned towards my students. I did not want to enter into a classroom that I did not know very well because I felt that would reinforce the feeling that gender and sexuality was an-add on topic, further tokenizing LGBTQ* people. Also, I felt students would feel more comfortable and safe expressing themselves openly with someone they knew. While I have facilitated this sort of workshop with classes I have not taught, I do feel the ideal is for educators to introduce these topics to their own classrooms.

My research with students consisted of three main elements: a survey asking students about their initial attitudes and perceptions around LGBTQ* issues in their school; a workshop where students learned about LGBTQ* terms, discussed gender and sexuality, and made a collaborative piece of art; and a survey given after the workshop reassessing their attitudes and perceptions around LGBTQ* issues in their school. Students needed to give consent to participate in the workshop and have their survey answers and workshop art analyzed. The class's educational assistant was provided with a script to explain each component. She administered and collected consent forms as well as the pre and post-workshop surveys. I was not aware of who consented until the day of the workshop.

In this section, I will discuss the format and findings from the initial surveys. The pre-workshop survey had 12 questions. Twenty-seven surveys were handed-in. The last question was a selfidentification question where students were asked to check-off any and all labels that they felt accurately represented their gender identity and/or sexual orientation. It should be noted that because I did not expect students to know all of the terms before the workshop, I provided them with short definitions beside each label I listed. I also gave students the option to check "I don't know", "I prefer not to label myself", and "other" with a blank space to write terms they might use. Twenty-four students checked off cisgender as their sole gender identity term. One student checked cisgender and also checked off transgender. Another student scrawled "I think?" next to cisgender. Both of these responses could be due to unclear definitions or they could indicate confusion about their gender identity. Another student checked off cisgender but also wrote under the header of gender identities, "myself (no joke)". In terms of sexual orientations, twenty-five students checked off "Straight/Heterosexual" as a label they identify with. One student checked off "I prefer not to label myself" and another student left this section blank. Overall, the majority of students initially identified as cisgender and heterosexual. Here are the pre-survey questions.

\section{Pre-Workshop Student Survey Questions}

1. Generally do you feel like your school is inclusive?

2. Generally do you feel like LGBTQ*-identifying people feel safe?

3. Do you feel comfortable talking about gender and/or sexuality in school? 
4. Do you feel like gender and/or sexuality is an important topic to discuss at school?

5. Are you aware of any clubs that your school offers to support LGBTQ* students?

6. Are you aware of any teachers, coaches, or community members in your school who identify as LGBTQ*?

7. Do you feel like the majority of staff are supportive of LGBTQ* identifying people?

8. Have you learned a lot about LGBTQ* issues in school?

9. Do you know what the LGBTQ* acronym stands for?

10. Do you feel very knowledgeable about LGBTQ* issues?

11. Would you like to learn more about LGBTQ* issues in schools?

I will group these eleven questions into three categories: how the students perceived their school's attitudes towards LGBTQ* people; how knowledgeable students felt about LGBTQ* issues; and how they felt about learning about LGBTQ* issues in schools. For each question, I gave students the option of circling "not at all", "a little bit" "yes" or "very much so".

\section{III.1 Initial attitudes towards school climate: Generally inclusive}

For the most part, the students' responses suggest that they felt their school was an inclusive space for LGBTQ* people. Encouragingly, $86 \%$ of students indicated that they felt the majority of staff at their school were supportive of LGBTQ* people (only $0.07 \%$ stated "not at all" to this prompt). When asked if they thought LGBTQ* students felt safe in their school, $15 \%$ of students indicated "very much so", 50\% of students replied "yes", 30\% circled "a little bit" and $0.04 \%$ marked "not at all". While the majority of students indicated they thought their school was "safe" or "inclusive", most students marked that they had only learned "a little bit" about LGBTQ* issues in schools (65\%). Likewise most students circled that they were only "a little bit" $(42 \%)$ aware of queer educators, coachers, or local community members. An equal amount of students (23\%) indicated "not at all" and "yes" to the question of knowing queer educators, coaches, or community members. These responses correspond with my suspicion that the school I was teaching at had a generally inclusive atmosphere, but like many schools, LGBTQ* people were not very visible nor was LGBTQ* content integrated into classroom learning.

\section{III.2 Initial knowledge levels: A little knowledgeable}

When students were asked about their own knowledge, the majority of students indicated they felt "a little bit" (62 \%) knowledgeable about LGBTQ* issues. When asked about if they knew what the LGBTQ* acronym stands for, the majority, but a far smaller amount of students, either indicated "yes" $(39 \%)$ or "a little bit" $(31 \%)$. This data suggests that students had a range of knowledge levels coming into the workshop.

\section{III.3 Initial interest level in learning about LGBTQ* issues in schools: Some resistance}

When I asked students about their desire to learn about LGBTQ* issues in schools, opinions were split. Most students (but by a small margin) marked that they wanted to learn "a little bit" about LGBTQ* issues in schools (43\%), although the second highest amount of students indicated they did not want to learn about queer issues at all (31\%). This was followed by $27 \%$ circling "yes" or 
"very much so". The fact that such a large number of students indicated they did not want to learn about LGBTQ* issues is intriguing. It seems to suggest resistance, which is puzzling since so many students indicated that they felt their school was inclusive and safe for LGBTQ* students.

I believe that these responses could be indicative of a queer-safe environment. At this school, students seemed to have some awareness of LGBTQ* issues, and felt their teachers were supportive, but did not necessarily want any further connection to or knowledge about queer people. This distancing of themselves to LGBTQ* people and issues suggests discomfort at the idea of queerness and otherness. This is the context of the class I worked with.

\section{IV. 'Start with Heart': Storytelling and its unraveling of identity}

To combat what I read as some initial discomfort at queerness - and coming back to Stephen's comment to "start with heart" - I developed a workshop that could engage all students in dialogue about difference and connection. The workshop was approximately two hours in length and took place over two regularly scheduled classes. Due to the scheduling of the school, the first half of the workshop took place on a Monday and the second half took place on a Tuesday. Thirty students consented to participate in the workshop.

For the first hour of the workshop, I asked learners to start with their hearts: reflect and share stories of difference and vulnerability. I began with some discussion around Ash Beckham's Ted Talk, "Coming out of your closet" (2013), where she locates coming out as a universal experience. She explains that coming out is not a purely LGBTQ* experience. I would, however, argue that it is a queer experience because it asks people to reflect and share some struggle or difference with others.

I also began the workshop with a discussion around the term queer. I invited students to reflect on and discuss what that term means to them. It should be noted that before I began the workshop, I emphasized that students should feel free to speak openly and honestly and not fear offending me or anyone else. I felt that vocalizing this was important, because we cannot expect people to use terminology sensitively if they do not fully understand it; this was one of the goals of the workshop after all, and it would be unfair to expect that students knew the complexities of these terms without being taught about them first. Many students expressed that they thought that queer was an offensive term. Some students noted they had heard it used in positive ways before. We therefore started the workshop on the footing that language is malleable and dependent on the meaning we assign it.

Because I wanted students to feel safe to share, I invited learners to paint their coming out stories on canvas tiles anonymously. I was not aware of the stories students choose to share, nor were other students. They spread out when they painted them. One student painted a grenade with a ticking clock. Another student drew headphones with various words coming out. Another drew a flower. Students were not given very much direction besides being told to represent a coming out story for themselves: a time when they felt different and/or shared it with others. Most students seemed highly engaged in this activity. Even students that I expected would be less interested took up the task with a quiet zeal. I believe that starting the workshop with this activity softened the topic for learners who might be tempted to state that queerness and LGBTQ* issues did not pertain to their lives.

Since we were working with paint, the canvas tiles had a night to dry, and we returned the next day, starting with LGBTQ* terms and some discussion about gender and sexuality (See Figure 1. in the Appendix for a picture of the finished canvas tiles). The second half of the workshop started with an interactive activity. In pairs, students matched definitions with terms that had been hung up around the room. They could discuss with their partner or ask me for help, and had to guess 
what definitions or fun facts matched with what terms. I explained to them that I wanted to start with what they knew already and go from there. This was to show them that it was okay to start with their knowledge base, and see what sort of preconceptions we might have. Many students knew terms like "gay", "lesbian", "bisexual". New terms for many students were "cisgender", "transgender", "genderqueer", "intersex", "Two-Spirit" and "pansexual". I took this opportunity to give more definitions, while also emphasizing that these terms are self-identification labels meaning they do not have stable meanings, but are instead constantly evolving.

After going over terms, I broke the class up into small stations (3-4 students). Four stations had discussion prompts, and the last station was a gluing station for our art project. The discussion stations were given a piece of paper, post-its, markers and approximately 3 minutes to answer their question. Examples of discussion prompts included:

1. Why do you think people are homophobic/biphobic/transphobic?

2. Do you think schools have a responsibility to teach students about gender and sexual diversity? Why or why not?

3. How do you think we can make schools more inclusive to LGBTQ* people and other minorities?

For the question of why they thought people are discriminatory, many of the groups wrote down "ignorance", "no education", and "religion". For the question of whether schools have a responsibility to teach about gender and sexual diversity, all groups said yes and gave reasons like "we should learn to be kind to each other", "we should stop bullying". Some students noted: "we can learn about LGBT history in class", or "have more workshops" for ways schools could be more inclusive. After all students had had a chance to answer each discussion prompt and glue some of the canvas tiles, we debriefed the workshop. We talked about what students had written for the discussion prompts, and talked about the canvas we created: how all of the tiles had been fitted together to create a collaborative piece of art. They then glued it together and could see a message I had previously painted on it: "Our stories. Our connections." I asked them why they thought we did this activity and why I might have chosen those words for the painting. Some students said we could see different people's stories. Another said it was more about how we are all different, and we could see that we've all been through "tough stuff". Ultimately, this activity stressed connectivity, and sought to accomplish three goals: help students become more aware of LGBTQ* identities; help students make connections between various forms of difference; and, help students see and accept difference in themselves. In other words, the main goal of the workshop was to queer the class through queering ourselves: coming in/out together through sharing stories that have shaped us.

\section{Coming in/out together: Building connections and combatting resistance}

After completing the workshop, students were asked to complete a post-workshop survey. The survey had many of the same questions from the first survey. It also gave students another opportunity to disclose their gender/sexual identities, and write any final comments about the workshop experience for them. One student disclosed that she was a lesbian, although the rest of the data remained the same. This same student wrote that "[a]s a lesbian I already knew a lot, but I'm really happy this happened, and people are choosing to learn". All the students that chose to write a comment left positive messages. A few students scrawled "Great workshop". One student said, "I enjoyed it". A few students commented how they wish they had more time for painting. These comments were certainly encouraging, and correlated for the most part with the answers students gave to other answers. I will now discuss those responses. 


\section{V.1 Follow-up attitudes towards school climate: Slightly more inclusive}

When asked "[h]ave your feelings about your school or classmates changed? (i.e. do you feel like your school is a safer space after this workshop)" student opinions were split. The majority replied "a little bit" (41\%). The second highest group stated "yes" (33\%) followed by "not at all" $(26 \%)$. No one answered "very much so" for this question. This suggests more work is required for a class to become queer-affirming than a single workshop or lesson.

\section{V.2 Follow-up knowledge levels: More knowledgeable}

When asked if they felt more knowledgeable about LGBTQ* issues, the majority of students noted "yes". Specifically, when asked if they know what the LGBTQ* acronym stands for now, 92\% students either replied "yes" (54\%) or "very much so" (38\%). Only $0.04 \%$ replied "not at all" or "a little bit" to that question. This indicates that students felt more knowledgeable about LGBTQ* issues after the workshop.

\section{V.3 Follow-up interest level in learning about LGBTQ* issues in schools: Less resistance}

While some resistance was expressed to learning about LGBTQ* issues in schools before the workshop, $82 \%$ of students replied "yes" (52\%) or "very much so" $(30 \%)$ to the question: "Would you say this workshop was a positive and/or empowering experience?" $15 \%$ said it was "a little bit" positive/empowering and $0.04 \%$ (1 person) said "not at all". It therefore seems that the workshop was a positive experience for the majority of students and lead some to feel their school is more accepting. The majority of students said they would only talk "a little bit" (65\%) more about this topic with their peers. Also, most students said they felt more comfortable talking about gender/sexuality in schools, but by a small margin.

\section{Conclusion and Recommendations}

In conclusion, facilitating this queer-affirming workshop confirmed two suspicions: that stories can be a great tool for educators to initiate conversations about gender and sexual diversity in their classrooms, and that ongoing integration of LGBTQ* content in classrooms will make for more sustained inclusivity in schools. The majority of schools utilize a queer-safe approach, which is certainly better than having no LGBTQ* safe policies, but nonetheless risks inadvertently invisibilizing or victimizing LGBTQ* people. A queer-affirming approach, on the other hand, moves beyond addressing harassment, and engages all school stakeholders in a continuous process of examination of hetero/cisnormativity. With a queer-affirming approach, students and teachers learn together about LGBTQ* perspectives and histories, and challenge the different/normal binary. Because a queer-affirming approach requires curricular reform, and provision of more resources and training for educators, it is more challenging for schools to realize. Ideally, preservice teachers should receive more training on gender and sexual diversity while they are completing their degrees and there should be more professional development opportunities for established educators. While these changes are dependent on universities and districts, one way that educators can independently begin to affirm queerness in their classroom is through fostering opportunities for themselves, their students, and community members to share stories of difference and vulnerability.

While telling stories in no way wins the battle of garnering full visibility for LGBTQ* people in schools, it does create a space where visibility for queer people is more possible. When learners are exposed to personal stories - and are taught to respectfully share and listen to difference - they 
are equally engaged in a process of reflection on how to be more accepting of difference in their day-to-day life. So how can educators do this when they have prescribed learning outcomes or big ideas they need to cover with their classes? One way teachers can integrate personal storytelling into their teaching is to create assignments and lessons that provide more instances for reflection and sharing. This certainly seems like an easier task for humanities teachers, specifically English Language Arts, Visual Arts, Drama and Music teachers, and so I would suggest further research for how to integrate this into math and science classes. Even before teachers could assign projects that are more reflective, they could facilitate a similar workshop to the one I discuss above. I would recommend doing this with students near the beginning of the year and to use it as a community-building activity.

All in all, if we can share stories of difference and vulnerability, we can queer schools: make them places where difference is our commonality, and normalcy is not the aim. Returning to my coming out story - to the resounding silence that greeted me as I realized my queerness - the main strategy I wish to impart to educators is to create communities of difference. Make room for personal stories in your classrooms. Share your own stories of difference and vulnerability, and facilitate opportunities for your students to do the same. If we can create opportunities for learners, community members, and ourselves to come out about how we are all different (queer), perhaps we will all be a little less lonely. And perhaps, just perhaps, when we come out in our schools, we can come in/to more inclusive and authentic learning spaces.

\section{REFERENCES}

Beckham, A. (2013). Coming Out of Your Closet. Retrieved from https:/ /www.youtube.com/ watch?v=kSR4xuU07sc

Chamberland, L. (2011). The Impact of Homophobia and Homophobic Violence on School Persistence and Academic Success: Key Findings. Montreal, QC: Université du Québec à Montréal.

Dorais, M. (2001). Mort ou fif: La face cachée du suicide chez les garçons. Montréal, QC: VLB éditeur.

Formby, E. (2015). Limitations of Focussing on Homophobic, Biphobic and Transphobic 'Bullying' to Understand and Address LGBT Young People's Experiences Within and Beyond School. Sex Education, 15(6), 626-15. doi:10.1080/14681811.2015.1054024

Freitag, M. (2013). A Queer Geography of a School: Landscapes of Safe(r) Spaces. Confero: Essays on Education, 1(2), 123-161. doi:10.3384/confero.2001-4562.13v1i21b

Gildersleeve, R. \& Kuntz, A. (2011). A Dialogue on Space and Method in Qualitative Research on Education. Qualitative Inquiry 17(1), 15-22.

Loftus, S., Higgs, J. \& Trede, F. (2011). Researching Living Practices. In Higgs, J, Titchen, A., Horsfall, D. \& Bridges, D. (Eds.), Practice, Education, Work \& Society: Creative Spaces for Qualitative Researching (Vol. 4, pp. 3-12). Rotterdam, Holland: Sense Publishers.

McNinch, J. \& Cronin, M. (2004). I Could Not Speak My Heart. In University of Regina Canadian Plains Research Center (Eds.), Education and Social Justice for Gay and Lesbian Youth. Regina, SK: 
Canadian Plains Research Center, University of Regina.

Phoenix, A. (2006). Intersectionality. European Journal of Women's Studies, 13(3), 187-192.

Rasmussen, M. L., \& Crowley, V. (2004). Editorial Overview: Wounded Identities and the Promise of Pleasure. Discourse 25(4), 427-430.

Rasmussen, M. L. (2016). What's the Place of Queer Theory in Studies of Gender, Sexuality, and Education on the Periphery? Review of Education, Pedagogy, and Cultural Studies, 38 (1), 73. doi:10.1080/10714413.2016.1119644

Rayside, D. (2014). The Inadequate Recognition of Sexual Diversity by Canadian Schools: LGBT Advocacy and its Impact. Journal of Canadian Studies/Revue d'Études Canadiennes, 48(1), 190-225.

Rayside, D. (2008). Queer Inclusions, Continental Divisions: Public Recognition of Sexual Diversity in Canada and the United States. Toronto: University of Toronto Press.

Saewyc, E., Skay, C., Pettingell, S., Reis, E., Bearinger, L., Resnick, M, Murphy, A., \& Combs, L. (2006). The Hazards of Stigma: The Sexual and Physical Abuse of Gay, Lesbian, and Bisexual Adolescents in the US and Canada. In LGBTQ Youth in Child Welfare, ed. Rob Woronoff and Gerald P. Mallon. Special issue, Child Welfare 85(2): 195-213.

Saewyc, E., Poon, C., Wang, N., Homma, Y., Smith, A., \& the McCreary Centre Society (2007). Not Yet Equal: The Health of Lesbian, Gay and Bisexual Youth in BC. Vancouver, BC: McCreary Centre Society.

Short, D. (2013). Don't Be So Gay! Queers, Bullying, and Making Schools Safe. Vancouver, BC: University of British Columbia Press.

Smith, M. (2008). Political Institutions and Lesbian and Gay Rights in the United States and Canada. New York, United States: Routledge.

Storey, E.E. \& Fobes, S. (n.d.). LGBTTTIQQ2SAA+ DEFINITIONS. Revel and Riot. Retrieved from http://www.revelandriot.com/resources/lgbtq-and-trans-definitions /

Sykes, H. (1998). Turning the Closets Inside/Out: Towards a Queer-Feminist Theory in Women's Physical Education. Sociology of Sport Journal, 15(2), 154-173.

Taylor, C., Peter, T., Campbell, C., Meyer, E., Ristock., J., Short, D. (2015). In Egale Canada Human Rights Trust (Eds.), Every Teacher Project: Final Report on LGBTQ-Inclusive Education in Canada's K-12 schools. Winnipeg, MB: The Manitoba Teachers' Society.

Taylor, C. \& Peter, T. (2011). In Egale Canada Human Rights Trust (Eds.), Every Class in Every School: Final Report on the First National Climate Survey on Homophobia, Biphobia, and Transphobia in Canadian schools. Toronto, ON: Egale Canada Human Rights Trust. 
Toomey, R. B., McGuire, J. K., \& Russell, S. T. (2012). Heteronormativity, School Climates, and Perceived Safety for Gender Nonconforming Peers. Journal of Adolescence, 35(1), 187-196.

Walton, G. (2004). Bullying and Homophobia in Canadian Schools: The Politics of Policies, Programs, and Educational Leadership. Journal of Gay and Lesbian Issues in Education, 1(4), 23-36.

Wiesel, E. (1992). Foreword. In G. Annas \& M. Grodin (Eds.), The Nazi Doctors and the Nuremberg Code (pp. 1-9). New York, United States: Oxford University Press, Inc.

\section{APPENDIX}

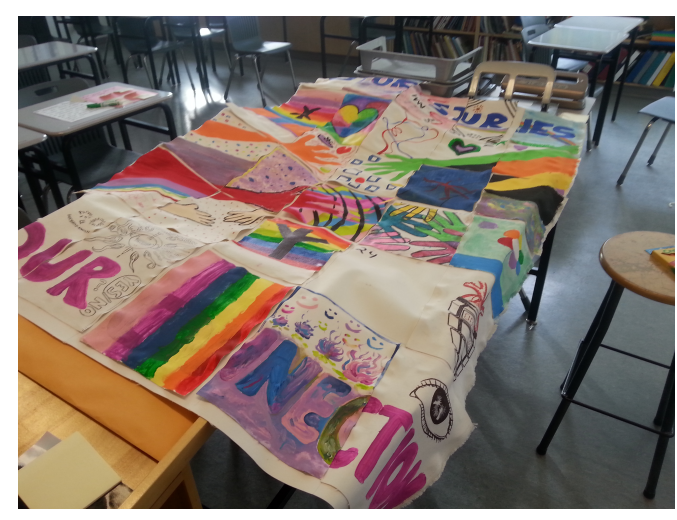

Figure 1: Finished Canvas Tiles (Cavanaugh, 2016) 